P-ISSN: 2541-6960; E-ISSN: 2549-8754

Yupa: Historical Studies Journal

Vol. 3 No. 2, 2020 (69-78)

http://jurnal.fkip.unmul.ac.id/index.php/yupa

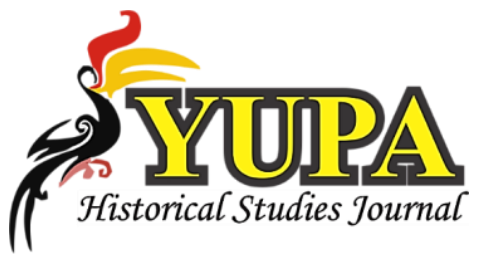

\title{
Pergolakan Politik Kasultanan Demak dan Ambisi Arya Penangsang sebagai Sultan Demak ke-4 Tahun 1546-1549
}

Anung Jati Nugraha Mukti ${ }^{1}$, Wahyu Djoko Sulistyo ${ }^{2}$

Jurusan Sejarah Universitas Negeri Malang, Jalan Semarang No. 5, Indonesia

${ }^{1}$ Jatianung@gmail.com, ${ }^{2}$ wahyu.fis@um.ac.id

$\begin{array}{ccc}\text { Received } & \text { Accepted } & \text { Published } \\ 15 / 06 / 2020 & 07 / 07 / 2020 & 31 / 07 / 2020\end{array}$

\begin{abstract}
Through historical methods, this article discusses the political upheaval that occurred in the Sultanate of Demak and the ambitions of Arya Penangsang as the 4th Sultan of Demak since 1546-1549. The political upheaval arose after the death of Sultan Trenggono as the 3rd Sultan of Demak 1546 and adopted his son, Sunan Prawoto as the 4th Sultan of Demak. The appointment caused deep disappointment to Arya Penangsang because he considered himself the right to serve as the 4th Sultan of Demak. Before Sultan Trenggono was appointed as the 3rd Sultan of Demak, there was an incident of the murder of Prince Sekar Seda Lepen, who was none other than the father of Arya. The political upheaval in the Sultanate of Demak did not stop there, the emergence of a new figure from the son-in-law of Sultan Trenggono who was predicted to be able to carry out his duties as a Sultan championed by Sunan Kalijaga, adding to the complicated political upheaval in the Demak Kasforest and Arya Penangsang's ambitions in his efforts to avenge his father's death. and retake the throne of Sultan Demak back to him.
\end{abstract}

Keywords: Sultanate of Demak. Politic, Arya Penangsang, Jaka Tingkir

\begin{abstract}
Abstrak Melalui metode sejarah, artikel ini membahas tentang pergolakan politik yang terjadi di Kasultanan Demak dan ambisi Arya Penangsang sebagai Sultan Demak ke-4 sejak tahun 15461549. Pergolakan politik tersebut timbul pasca wafatnya Sultan Trenggono sebagai Sultan Demak ke-3 1546 dan mengangkat anaknya yaitu Sunan Prawoto sebagai Sultan Demak ke-4. Pengangkatan tersebut menimbulkan kekecewaan yang mendalam terhadap Arya Penangsang karena menilai dirinyalah yang berhak menjabat sebagai Sultan Demak ke-4. Sebelum Sultan Trenggono diangkat menjadi Sultan Demak ke-3, terjadi sebuah peristiwa pembunuhan Pangeran Sekar Seda Lepen, yang tidak lain adalah ayah dari Arya penangsang hal tersebut menjadi dasar kekecewaan sekaligus pangkal dari permasalahan pergolakan politik di Kasultanan Demak. Pergolakan politik di Kasultanan Demak tidak berhenti sampai disitu, munculnya sosok baru dari menantu Sultan Trenggono yang digadang-gadang mampun mengemban tugas sebagai Sultan yang dijagokan oleh Sunan Kalijaga, menambah rumit pergolakan politik di Kasutanan Demak dan ambisi Arya Penangsang dalam usahanya menuntut balas atas kematian ayahnya serta merebut kembali tahta Sultan Demak kembali kepada dirinya.
\end{abstract}

Kata kunci: Kasultanan Demak, Politik, Arya Penangsang, Jaka Tingkir 


\section{PENDAHULUAN}

Istilah politik secara teoritis memiliki beragam makna, diantaraya menurut Deliar Noer (1983) politik adalah segala aktivitas atau sikap yang berhubungan dengan kekuasaan dan yang bermaksud untuk mempengaruhi, dengan jalan mengubah atau mempertahankan, suatu macam bentuk susunan masyarakat. Selanjutnya menurut Miriam Budiardjo (1982), politik pada umumnya merupakan bermacam-macam kegiatan didalam suatu system politik (negara) yang berkaitan dengan proses menentukan tujuan dari sistem tersebut dan melaksanakan tujuantujuan tersebut. Berdasarkan dua pengertian tersebut, dapat diketahui bahawa pada dasarnya mengandung persamaan dalam hal sudut pandang politik sebagai suatu kegiatan, adapun perbedaan dalam hal ini adalah bentuk kegiatan yang dilaksanakan.

Dalam kegiatan politik untuk mencapai tujuan yang direncanakan, adalah suatu keniscayaan apabila terjadi konflik. Konflik politik pada dasarnya adalah perbedaan pendapat, persaingan dan pertentangan diantara sejumlah individu, kelompok ataupun organisasi dalam upaya mendapatkan dan atau mempertahankan sumber-sumber dari keputusan yang dibuat dan dilaksanakan oleh pemerintah (Cholisin, 2007). Bahkan secara fungsionalitas operasional pengertian politik memang sangat dekat dengan konflik politik, menurut Kartono (1989) adalah semua usaha dan perjuangan individu serta kelompok dengan menggunakan macam-macam alat, cara dan alternatif tingkah laku untuk mencapai satu tujuan terbatas sesuai dengan ide individu atau ide kelompok dalam suatu sistem kewibawan yang integral.

Pada dasarnya konflik politik bukan hanya kepentingan individu saja, melainkan juga kepentingan kelompok. Konflik politik di Indonesia dalam kurun waktu abad ke-21 ini, bisa disebut konflik politik pemilu presiden adalah konflik yang cukup menyita perhatian, namun ternyata di Indonesia konflik politik yang serupa juga pernah terjadi pada kurun waktu tahun 1546-1549 di Kasultanan Demak. Bahkan, di waktu yang sama konflik tersebut juga terjadi di Kalimantan (Azmi, 2017). Konflik politik tersebut mengakibatkan pergolakan yang cukup hebat bahkan konflik ini bukan hanya melibatkan tokoh politis pada saat itu, melainkan juga melibatkan tokoh wali sebagai ulama yang terkait secara tidak langsung dalam peristiwa tersebut. Konflik tersebut bermula ketika wafatnya Sultan Trenggono sebagai Sultan Demak ke-3 kemudian mengangkat anaknya untuk dijadikan Sultan Demak ke-4.

Sepeninggalan Sultan Trenggono terjadi pegolakan politik di Kasultanan Demak. Sultan Trenggono wafat pada tahun 1546 ketika melakukan ekspedisi perluasan kekuasaan Kasultanan Demak. Kasus pembunuhan terhadap Sultan Trenggono bermula ketika Sultan Trenggono melakukan penyerangan di Panarukan yang merupakan bagian dari wilayah kekuasaan Blambangan. Pada saat Sutan Trenggono bermusyawarah bersama adipati untuk melakukan serangan selanjutnya, putra Bupati Surabaya yang berusia 10 tahun dan yang bertugas sebagai pelayan sangat tertarik dengan jalannya rapat sehingga tidak dengar perintah Sultan Trenggono 
untuk menyingkir. Karena tidak menedengarkan perintah tersebut, Sultan Trenggono marah dan memukul anak tersebut, sesudah mendapatkan pukulan dari Sultan Trenggono, anak itu sontak membalas dengan menusukkan pisau ke dada Sultan Trenggono. Akibatnya Sultan Trenggono tewas dan jenazahnya dibawa pulang ke Demak (Adji \& Achmad, 2014).

Sunan Giri dengan sesepuh Kasultanan Demak mengadakan diskusi kemudian bersepakat mengangkat Sunan Prawoto sebagai Raja Demak keempat dengan gelar Sultan Syah Alam Akbar Jiem-Boen-ningrat IV setelah kematian Sultan Trenggono. Pada tahun 1548 Sunan Prawoto memiliki cita-cita untuk mengislamkan seluruh Jawa, serta berkuasa seperti Sultan Turki. Citacita Sunan Prawoto pada kenyataannya tidak pernah tercapai, Sunan Prawoto lebih sibuk sebagai ahli agama daripada mempertahankan kekuasaannya. Satu persatu daerah bawahan Demak yang pernah ditahlukkan Sultan Trenggono, berkembang bebas, sedangkan Demak tidak mampu menghalanginya. Akhirnya, pada masa pemerintahan Sunan Prawoto Kasultanan Demak tidak memperluas wilayah kekuasaan, justru terjadi kemunduran (Abimanyu, 2013).

Arya Penangsang merasa lebih berhak menduduki tahta sebagai raja Demak ke-4 karena sebelum Sultan Trenggono dilantik menjadi Sultan Demak ke-3, terjadi sebuah pristiwa pembunuhan Pangeran Sekar Seda Lepen ayah Arya Penangsang oleh Sunan Prawoto. Sunan Prawoto adalah putra Sultan Trenggono, membunuh Pangeran Sekar Seda Lepen. Dari segi usia, Pangeran Sekar Seda Lepen memang lebih tua sehingga merasa lebih berhak atas tahta Kasultanan Demak dari pada Sultan Trenggono. Namun Pangeran Sekar Seda Lepen lahir dari selir Raden Patah, yaitu putri Adipati Jipang, sedangkan Sultan Trenggono lahir dari permaisuri putri Sunan Ampel. Sehingga dari segi kedudukan memang Pangeran Sekar Seda Lepen harus mengakui kedudukan dari Sultan Trenggono yang merasa lebih berhak menduduki tahta Kasultanan Demak (Muljana, 2005).

Kasultanan Demak memiliki adat pewaris tahta kursi raja adalah putra yang lahir dari permaisuri. Peristiwa pembunuhan Pangeran Sekar Seda Lepen menjadi pangkal pergolakan politik di Kasultanan Demak. Dalam topik ini yang menjadi sorotan adalah analisis bagaimana proses dan cara pergantian kekuasaan pasca wafatnya Sultan Trenggono. Secara langsung terdapat tiga kubu yang berkonflik yatu kubu Arya Penangsang, Keturunan Sultan Trenggono dan Joko Tingkir sebagai menantu Sultan Trenggono yang dianggap cakap dan berhak mengemban tugas sebagai Sultan Demak ke-4. Ketiga kubu ini memiliki dasar anggapan tersendiri mengapa dirinya berhak sebagai Sultan Demak ke-4. Pergolakan ini mengakibatkan perang saudara diantara keluarga Kasultanan Demak dan berakhir dengan keruntuhan Kasultanan Demak.

\section{METODE}

Artikel ini disusun berdasarkan metode sejarah yang terdiri dari empat tahapan, yaitu: heuristik, kritik, interpretasi dan historiografi (Kuntowijoyo, 2003). Tahap pertama penulis 
melakukan heuristik dengan cara studi pustaka, dalam hal ini peneliti melakukan pengumpulan sumber sekunder (berupa buku teks Kerajaan Islam Demak : Api revolusi islam di tanah Jawa, Karebet vs Penangsang : Perebutan Tahta Psca Runtuhnya Majapahit. Jakarta: Imania, KerajaanKerajaan Islam Pertama di Jawa : Kajian Sejarah Politik abad ke-15 dan ke-16 dll). Sumbersumber tersebut diperoleh dari Perpustakaan Pusat Universitas Negeri Malang, Perpustakaan Jurusan Sejarah Universitas Negeri Malang, Perpustakaan Daerah Tulungagung dan Perpustakaan pribadi dari penulis.

Tahap kedua penulis melakukan kritik sumber, hal ini bertujuan untuk melihat autentitas sumber baik keaslian sumber, tanggal, waktu pembuatan, serta pengarang. Kritik sumber terdiri dari dua jenis kritik yaitu, kritik ekstern dan intern. Kritik sumber dalam penelitian ini adalah membandingan informasi sebelumnya yang telah diketahui melalui sumber literatur dengan informasi yang terdapat pada literatur yang tersedia, baik berupa foto dokumentasi maupun narasi dari arsip. Kesesuaian informasi dari literatur telah ditemukan, sehingga tahap kritik sumber dinyatakan valid. Adapun kendala informasi terletak pada beberapa sumber literatur yang tidak menyantumka tahun secara urut, sehingga dapat mengakibatkan tidak kronologisnya suatu kejadian, namun permasalah ini mampu diatasi oleh penulis dengan membaca berbagai literatur yang relevan.

Tahap ketiga setelah melakukan kritik sumber adalah interpretasi, yaitu menafsirkan fakta-fakta yang telah valid, kemudian dianalisa yang pada akhirnya akan menghasilkan suatu rangkaian peristiwa. Penulis dituntut untuk cermat dalam mengungkapkan data-data yang diperoleh (Kuntowijoyo, 2005). Dalam hal ini kendala peneliti adalah memisahkan data berupa mitos dengan fakta. Pada periode ini penulisan sejarah Indonesia mengalami banyak campuran antara fakta dengan mitos sehingga hal tersebut perlu dipilah secara teliti untuk menguraikan fakta dan mampu menghasilkan historiografi yang analitis, kritis dan ilmiah.

Tahap keempat yaitu historiografi, yaitu penulisan sejarah gambaran masa lampau yang tersusun secara sistematis, bulat, dan jelas dalam bentuk cerita sejarah, atau dengan istilah lain historiografi disebut dengan penulisan sejarah. Dalam hal ini peneliti telah berhasil menempuh ketiga tahapan metode penelitian kemudian menuliskannya dalam bentu teks sejarah. Tahap historiografi ini, penulis berusaha menyusun cerita sejarah berdasarkan kronologi dan berdasarkan pada tema tertentu serta berpedoman dengan prinsip kebenaran secara objektif dalam sejarah agar penelitian ini mampu menghasilkan cerita sejarah yang dapat dipertanggungjawabkan secara ilmiah oleh penulis.

\section{HASIL DAN PEMBAHASAN}

\section{Latar Belakang Timbulnya Pergolakan Politik di Kasultanan Demak}


Pada tahun 1521 Pati Unus wafat, hal tersebut merupakan cikal bakal terjadinya pergolakan politik di Kasultanan Demak, ketika melakukan penyerangan Portugis di Malaka. Kekosongan kekuasaan di Kerajaan Demak menyebabkan perebutan kursi raja Kerajaan Demak oleh keturunan keluarga Kerajaan Demak. Peristiwa ini menimbulkan peperangan berkepanjangan yang berakhir dengan kehancuran kerajaan. Perebutan kekuasaan terjadi antara keturunan keluarga Kerajaan Demak yaitu Pangeran Sekar Seda Lepen dengan Pangeran Trenggono. Kedua pangeran menilai berhak menduduki tahta Kerajaan Demak. Dari segi usia, Pangeran Sekar Seda Lepen lebih tua sehingga merasa lebih berhak atas tahta Kerajaan Demak dari pada Pangeran Trenggono. Namun Pangeran Sekar Seda Lepen lahir dari selir Raden Patah, yaitu putri Adipati Jipang, sedangkan Pangeran Trenggono lahir dari permaisuri putri Sunan Ampel. Pangeran Trenggono merasa lebih berhak menduduki tahta Kerajaan Demak (Muljana, 2005). Adat Kerajaan Demak pewaris tahta Sultan adalah putra yang lahir dari permaisuri.

Tahun 1546 Sunan Giri dengan sesepuh Kasultanan Demak bersepakat mengangkat putra sulung Sultan Trenggono, yaitu Sunan Prawoto sebagai Raja Demak keempat dengan gelar Sultan Syah Alam Akbar Jiem- Boen-ningrat 4. Sunan Prawoto dinobatkan sebagai Sultan karena merupakan keturunan langsung dari Sultan Demak 3 yaitu Sultan Trenggono. Pelantikan Sunan Prawoto Menjadi Sultan Demak, semakin membuat Arya Penangsang geram

Sunan Prawoto memindahkan ibukota Kasultanan Demak dari Bintara ke daerah bukit Prawoto di desa Prawoto, Sukojiwo, Pati. Kelemahan Sunan Prawoto dalam memerintah Kerajaan Demak sejalan dengan catatan Manuel Pinto dari Portugis. Akibat ketidak seriusan Sunan Prawoto menjalankan Kerajaan Demak, banyak wilayah bawahan Demak seperti Banten, Cirebon, Surabaya, dan Gersik melepaskan diri dari Demak (Adji \& Achmad, 2014).

\section{Fase Pergolakan Politik di Kasultanan Demak}

Tahun 1546, Sultan Trenggono wafat. Hal ini mengakibatkan kekosongan kepala pemerintahan Kerajaan Demak. Sunan Giri dengan sesepuh Kerajaan Demak bersepakat mengangkat putra sulung Sultan Trenggono, yaitu Sunan Prawoto sebgai Sultan Demak keempat dengan gelar Sultan Syah Alam Akbar Jiem-Boen-ningrat IV. Sunan Prawoto memiliki cacat mata yaitu buta. Kebutaan Sunan Prawoto ini karena kutukan pamannya sendiri, saat Pangeran Prawoto muda, Sunan Prawoto membunuh pamannya karena pemberontakan yang dilakukannya (Purwadi, 2010).

Pelantikan Sunan Prawoto telah membuat Arya Penangsang kecewa. Arya Penangsang murka karena dendam atas kematian Ayahnya. Akhirnya Arya Penangsang mengirim utusan untuk membuhuh Sunan Prawoto beserta keluarganya. Pada tahun 1546 Ratu Kalinyamat, yang merupakan adik Sunan Prawoto, menemukan bukti bahwa Sunan Kudus terlibat pembunuhan kakaknya, kemudian Ratu Kalinyamat berinisiatif datang dari Jepara ke Kudus meminta pertanggungjawaban atas perbuatannya tersebut. Namun jawaban Sunan Kudus, Sunan Prawoto 
meninggal dikarenakan karmanya sendiri. Mendengar jawaban tersebut Ratu Kalinyamat dan Pangeran Hadiri memutuskan untuk kembali ke Jepara. Rombongan Ratu Kalinyamat dan suaminya, Pangeran Hadiri telah jauh meninggalkan wilayah Kudus, meskipun begitu mereka telah lupa bahwa mereka baru saja masuk kedalam wilayah musuh. Tak terbersit sedikitpun dibenak Pangeran Hadiri jika dibelakang, ada rombongan tengah mengejar yaitu pasukan tempur Arya Penangsang. Hanya Ratu Kalinyamat yang mendapatkan firasat yang tidak mengenakkan suaminya (De Graaf, 1985)

Pertempuran tak terelakkan lagi, beberapa prajurit Jipang tewas terbunuh oleh Ratu Kalinyamat. Sembari terus memacu kudanya kencang, Ratu Kalinyamat mencoba menyerang Patih Manahun, abdi Arya Penangsang yang paling setia. Patih Matahun mencoba menghindari serangan tersebut. Ratu Kalinyamat, Putri Sultan Trenggono ini memang mahir dalam ilmu perang. Jarang bisa ditemukan sosok seperti ini, walaupun seorang laki-laki sekalipun (Hayati, 2000).

Tiba tiba Terdengar teriakan-teriakan pasukan Jipang ditengah-tengah pertempuran. Teriakan-teriakan itu bersahut-sahutan: "Pangeran Hadiri tewas" Ratu Kalinyamat terkejut mendengar bunyi teriakan-teriakan itu. Ternyata, suaminya sendiri, Pangeran Hadiri terbunuh oleh pasukan Jipang. Ratu Kalinyamat yang telah menjadi Janda pun akhirnya merapat ke kubu Jaka Tingkir-Sunan kalijaga untuk membalas kematian suaminya (Purwadi, 2010).

Tahun 1547 terjadi pertemuan antara Sunan Kudus dengan Sunan Kalijaga, keduanta membicarakan ketegangan antara Demak dengan Jipang. Pandangan Sunan Kalijaga tentang keberpihakan Sunan Kudus terhadap Arya Penangsang diakui kebenarannya oleh Sunan Kudus. Sunan Kalijaga memohon kepada Sunan Kudus agar para sepuh (wali) sebagai ulama mampu menempatkan diri sebagai orang tua sehingga tidak ikut campur dalam urusan "rumah tangga" anak-anak. Biarkanlah urusan tata negara dilakukan oleh ahlinya masing-masing. Para wali adalah ahli dakwah bukan ahli tata negara. Jangan sampai para wali terpecah belah karena berpihak kepada salah satu yang berselisih (Maharsi, 2005)

Upaya yang dilakukan oleh para ulama ini, tidak membuahkan hasil dan malah terjadi Penolakan dari pihak Arya Penangsang dengan mengadakan saimbara, untuk membunuh Jaka Tingkir pada Tahun 1547. Empat anggota prajurit pilihan yang diambil dari anggota pasukan khusus segera ditugaskan menuju Pajang. Namun, Jaka Tingkir adalah sosok manusia yang dikenal digdaya tubuhnya kebal senjata tajam, meskipun dalam kondisi tidur, kesaktian ilmu Lembu Sekilan yang telah dipelajarinya dari Ki Ageng Banyubiru masih tetap aktif melindungi sang pemilik (Susetya, 2011).

Setelah lima bulan berlalu dari berita kematian Ratu Kalinyamat, ada seorang pemuda datang ke Kadipaten Pajang untuk mengabarkan kepada Jaka Tingkir bahwa Ratu Klainyamat masih hidup dan meminta bantuan kepada Jaka Tingkir untuk menyiapkan pasukan agar 
mengawal keberangkatannya dari Desa tempatnya diselamatkan ke Gunung Danaraja untuk bertapa agar dapat membunuh Arya Penangsang. Keluarga besar Trenggono telah berhasil disingkirkan dengan sempurna oleh Arya Penangsang, sehingga kini Kasultanan Demak behasil dikuasai oleh Arya Penangsang. Mendengar berita tersebut, Jaka Tingkir yang merupakan menantu dari Sultan Trenggono akhirnya mengirimkan pasukan untuk mengawal Ratu Kalinyamat ke tempat pertapaannya(Mahfud, Y.M, 2015).

Arya Penangsang ternyata sudah mendengar pergerakan dari Jaka Tingkir yang ikut campur dalam urusan, sehingga Arya Penangsang berupaya untuk menyingkirkannya juga. Berbagai percobaan pembunuhan yang dilakuan oleh Arya Penangsang kepada Jaka Tingkir, hal ini membuat Jaka Tingkir geram dan murka. Akhirnya Jaka Tingkir memanggil Pemanahan, Penjawi dan Juru Mertani untuk berdiskusi mengatur strategi menghadapi Arya Penangsang, yang secara terus terang akan menyerang Pajang. Jaka tingkir kemudian membuka sayembara untuk mengalahkan Arya Penangsang. Siapa saja yang bisa membunuh Arya Penangsang akan diberi tanah perdikan di Mentaok dan Pati. Sayembara dilakukan karena rasa sakit hati Jaka Tingkir yang ingin dibunuh oleh Arya Penangsang dan sekaligus memenuhi keinginan dari Ratu Kalinyamat. Ki Ageng Pemanahan dan Ki Ageng Penjawi atau Ki Ageng Pati sanggup mengikuti sayembara membunuh Arya Penangsang, kemudian mereka berdua Ki Ageng Pemanahan dan Ki Ageng Penjawi memikirkan cara membunuh Arya penangsang (Wahyudi, 2009)

\section{Fase Akhir dari Pergolakan Politik Kerajaan Demak}

Ki Ageng Pemanahan serta KI Ageng Penjawi, Juru Mrentani, dan Raden Bagus mendapatkan restu dari Jaka Tingkir untuk mengikuti sayembara pembunuhan Arya Penangsang kemudian menyusun strategi. Pemanahan beserta rombongan meninggalkan Pajang, menemui salah seorang tukang rumput untuk kuda Gagakrimang milik Arya Penangsang. Salah satu telinga dari tukang rumput diiris hingga mengucurkan darah oleh Pemanahan, kemudian Juru Mrentani mengkalungkan surat tantangan yang ditujukan kepada Arya Penangsang. Sambil meraungraung kesakitan, tukang rumput menghadap Arya Penangsang.

Mendengar laporan dari tukang rumput yang telah diiris salah satu telinganya oleh Pemanahan, kemudian ia menghadap Arya Penangsang. Sesudah melaporkan apa yang terjadi, tukang rumput menyerahkan surat tantangan yang dikalungkan di lehernya kepada Arya Penangsang. Arya Penangsang yang sedang makan sontak berhenti bersantap untuk membaca surat tantangan. Surat tantangan belum selesai dibaca, Arya Penangsang berang bukan kepalang. Kemurkaannya ditumpahkan dengan memukul piring tempat nasinya hingga terbelah menjadi dua (Adji \& Achmad, 2014).

Arya Penangsang segera naik kepunggung kuda Gagakrimang menuju Sungai Bengawan Solo. Arya Penangsang yang terus ditantang oleh Pemanahan beserta pasukannya menyebrangi Bengawan Solo, sungai yang diyakini dapat melemahkan kesaktian penyebrangnya. Selagi Arya 
Penangsang menyebrangi sungai, pasukan Pajang menghujani peluru, tombak, dan panah. Hingga lambung Arya Penangsang yang terkena tombak menjuntaikan ususnya keluar. Sembari memacu Gagakrimang menuju sebrang sungai, Arya Penangsang menyampirkan usunya ke pusaka Kyai Setan Kober yang terselip di pinggang Setibanya di seberang sungai Bengawan Sore, Arya Penangsang mengamuk bagai banteng terluka. Banyak pasukan Pemanahan tewas terinjak kaki kuda Gagakrimang. Melihat pasukan Pajang semakin menipis. Pemanahan, Penjawi, dan Raden Bagus menghadapi Arya Penangsang. Manakala Arya Penangsang dapat menangkap Raden Bagus, Juru Mretani meminta Arya Penangsang untuk membunuh Raden Bagus dengan keris pusaka Kyai Setan Kober.

Arya Penangsang dengan amarah berkobar-kobar menghunus Kyai Setan Kober. Hasrat hati ingin membuhuh Raden Bagus, namun keris pusaka Kyai Setan Kober justru mengakhiri hidup Arya Penangsang sesudah memutus ususnya sendiri (Abimanyu, 2013). Sesudah Arya Penangsang menghembuskan napas terakhir, Pemanahan memenggal kepalanya. Arya Penangsang wafat pada tahun $1549 \mathrm{M}$.

Setelah Arya Penangsang meninggal, Pemanahan, Penjawi, Juru Mretani, dan Raden Bagus menghadap Adipati Hadiwijaya untuk melaporkan keberhasilannya dalam mengikuti sayembara. Adipati Hadiwijaya memenuhi janjinya dengan memberikan tanah Pati pada Penjawi yang dikenal dengan Ki Ageng Pati, dan memberikan tanah yang suatu saat dijadikan wilayah Kasultanan Mataram kepada Pemanahan pada tahun 1556. Selain mendapatkan hadiah dari Adipati Hadiwijaya berupa lahan Mataram, ia juga mendapatkan harta benda maupun para putri dari Ratu Kalinyamat yang telah menyelersaikan tapa brata di Gunung Danaraja (Purwadi \& Maharsi, 2005), namun hadiah dari Ratu Kalinyamat diserahkan oleh Pemanahan kepada Jaka Tingkir. Sang adipate menilai putri dari Kalinyamat terlalu muda, akhirnya putri tersebut dititipkan kepada Pamanahan untuk dibesarkan.

\section{KESIMPULAN}

Konflik politik pada dasarnya adalah suatu keniscayaan dalam kancah perpolitikan. Salah satu konflik politik yang cukup mencolok adalah pemilu Presiden Indonesia pada abad ke-21. Dalam konflik tersebut banyak sekali intrik dan strategi politik yang dimainkan oleh pihak-pihak yang berkepentingan didalamnya. Namun jauh sebelum itu, pada zaman Kasultanan Demak juga sudah terjadi konflik politik yang mengakibatkan pergolakan yang cukup hebat. Konflik tersebut bermula ketika wafatya Sultan Trenggono sebagai Sultan Demak ke-3 dan mengangkat anaknya yaitu Prawoto sebagai Sultan Demak ke-4. Arya Penangsang menilai bahwa yang pantas mengemban tugas sebagai Sultan adalah dirinya, karena terjadinya insiden pembunuhan Pangeran Sekar Sedo Lepen oleh Sunan Prawoto yang bertujuan untuk melancarkan tujuan ayahnya yaitu Sultan Trenggono sebagai Sultan di Demak. Tahun 1546 pelantikan Sunan Prawoto 
telah membuat Arya Penangsang kecewa. Arya Penangsang murka karena dendam atas kematian ayahnya. Akhirnya Arya Penangsang mengirim utusan untuk membuhuh Sunan Prawoto beserta keluarganya. Sejak saat itulah Demak dan Jipang mengalami hubungan yang kurang baik.

Arya Penangsang berhasil membunuh seluruh keluarga dari Sultan Trenggono, terkecuali Ratu Kalinyamat yang ternyata masih selamat dan meminta bantuan kepada Jaka Tingkir. Ternyata Arya Penangsang telah mendengar berita tersebut, bahwa Jaka Tingkir berniat ikut membantu keluarga Sultan Trenggono karena Jaka Tingkir merupakan anak menantu dari Sultan Trenggono. Mendengar berita tersebut Arya Penangsang bergerak cepat dengan upayanya untuk menyingkirkan Jaka Tingkir, namun upayanya selalu gagal. Jaka Tingkir mengetahui gelagat busuk dari Arya Penangsang. Akhirnya Jaka Tingkir meminta bantuan kepada Pemanahan, Penjawi dan Juru Mertani untuk berdiskusi mengatur strategi menghadapi Arya Penangsang, yang secara terus terang akan menyerang Pajang. Jaka tingkir membuka sayembara mengalahkan Arya Penangsang dengan imbalan tanah perdikan.

Tahun 1549 Arya Penangsang gugur dalam pertempuran. Siasat yang dijalankan oleh Penjawi, Juru Mretani, dan Raden Bagus sukses dilaksanakan, akhirnya Adipati Hadiwijaya atau Jaka Tingkir memberikan imbalan yang setimpal kepada mereka. Syaimbara yang dilaksanakan Jaka Tingkir sukses meredakan pergolakan politik yang terjadi di Kasultanan Demak. Gugurnya Arya Penangsang ini sekaligus mengakhiri pergolakan politik kekuasaan yang terjadi di Kasultanan Demak pada 1546-1549.

\section{REFERENCES / REFERENSI}

Abdullah, R. (2015). Kerajaan Islam Demak: Api revolusi islam di tanah Jawa. Solo: AL Wafi Publishing.

Abimanyu, S. (2013). Babad Tanah Jawi Terlengkap dan Terasli. Jogjakarta: Laksana.

Adji, K. B \& Achmad, S. W. (2014). Sejarah Raja-Raja dari Mataram Kuno Hingga Mataram Islam. Yogyakarta: Araska.

Azmi, M. (2017). Islam di Kalimantan Selatan pada Abad Ke-15 sampai Abad Ke-17. Yupa: Historical Studies Journal, 1(1), 38-47.

Budiardjo, Meriam. (1982). Dasar-Dasar Ilmu Politik. Jakarta: Gramedia.

Cholisin. (2007). Dasar-dasar Ilmu Politik. Yogyakarta: UNY Press

Daliman. (2012). Islamisasi dan Perkembangan Kerajaan-Kerajaan Islam di Indonesia. Yogyakarta: Penerbit Ombak.

De Graaf, P. (1985). Kerajaan-Kerajaan Islam Pertama di Jawa: Kajian Sejarah Politik abad ke-15 dan ke-16. Jakarta: Grafiti Pers.

Hayati, C. d. (2000). Peranan Ratu Kalinyamat di Jepara pada abad 16. Jakarta: CV Prima Putra. 
Kartono, Kartini. (1989). Pendidikan Politik Sebagai Bagian dari Pendidikan Orang Dewasa. Bandung: Penerbit Mandar Maju

Mahfud, M. Y, Sumarno, Handayani, S. (2015). Konflik Politik Kerajaan Demak setelah Wafatnya Sultan Trenggono Tahun 1546-1549. UNEJ. https://repository.unej.ac.id/handle/123456789/63600?show=full.

Muljana, S. (2005). Runtuhnya Kerajaan Hindu Jawa dan Timbulnya Negara-Negara Islam di Nusantara. Yogyakarta: LKIS.

Noer, Deliar. (1983). Pengantar ke Pemikiran Politik. Jakarta: Rajawali.

Purwadi. \& Maharsi. (2005). Babad Demak: Perkembangan Agama Islam di Tanah Jawa. Jogjakarta: Tunas Harapan.

Purwadi. (2010). Babad Tanah Jawa. Yogyakarta: Panji Pustaka.

Susetya, W. (2011). Karebet vs Penangsang: Perebutan Tahta Pasca Runtuhnya Majapahit. Jakarta: Imania.

Wahyudi, A. (2009). Joko Tingkir Berjuang Demi Takhta Pajang. Pustaka Narasi. 